\title{
Rethinking Peripheral Sensitization, Peripheral Neuropathic Pain and the Putative Value of Topical Analgesics
}

\author{
Jan M Keppel Hesselink* \\ Professor of molecular pharmacology, Netherlands
}

Submission: November 01, 2017; Published: November 13, 2017

*Corresponding author: : Jan M Keppel Hesselink, Professor of molecular pharmacology, Institute for Neuropathic Pain, Spoorlaan 2a, 3735 MV

Bosch enDuin, Netherlands, Email: jan@neuropathie.nu

\section{Editorial}

One of the reasons we do not succeed in improving our analgesic regimes is anchored in our conservatism, conservatism related to the animal models we develop and use during the process of drug research and development, and in the targets we select. It will be clear to many specialists in the field, that if we optimize new lead molecules, based on old established molecules as gold standards, we will only succeed in improving marginally the treatment principle. In the best case, we will create new metoo analgesics. The degree of efficacy of prescribed analgesics and co-analgesics in neuropathic pain is all more or less in the same ball-park, and only little differences exist, mainly in side-effect profiles, drug-drug interactions and perhaps in the selected target populations for the clinical development. But, sadly enough, there are no major clinical relevant differences in magnitude of efficacy between the various analgesics and co-analgesics. More than $50 \%$ of all neuropathic pain patients are not responsive to treatment, and this reflects in the high Numbers Needed to Treat (NNT) for these analgesics.

This might start to change, if we learn to understand more deeply the pathogenesis of neuropathic pain in the various groups of patients. For instance, patients suffering from small fiber neuropathic pain and patients suffering from trigeminal neuralgia will have quite different pathogenetic networks, centrally, peripherally and at the level of the dermal tissue compartments. This needs to be reflected in the choices we make for pharmacotherapy.

\section{Three Actors Cross-Talking in the Epidermis}

In the dermal tissue compartment, there are three cells which interact and play a key role in analgesic and algesic mechanisms: the nociceptors (small nerve fibers), the keratinocytes and the immune-competent cells. These 3 cells are all capable of producing pro-inflammatory compounds and anti-inflammatory compounds and the cross-talk between the cells defines the outcome of the excitatory patterns of the nociceptor. The latter is a driver for peripheral sensitization and 'chronification' of pain. Keratinocytes for instance can produce both the algesic molecules ATP and CGRP, which are released through the activation of voltage-gated sodium channels ( $\mathrm{NaV}$ ) expressed on these keratinocytes. The release of ATP by the keratinocytes subsequently can activate purinergic receptors, which are expressed on epidermal nerve endings, etc [1] (Figure 1).

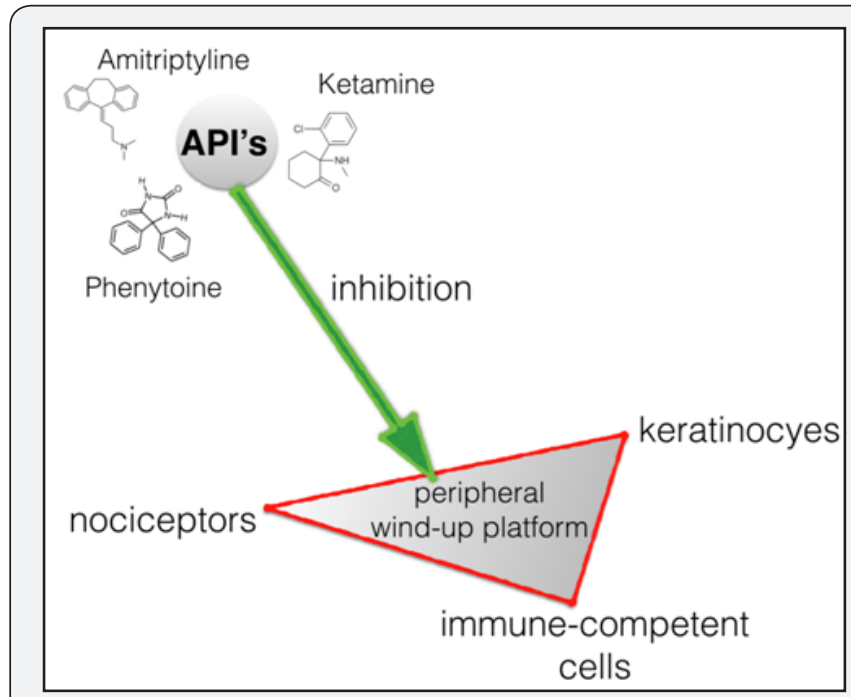

Figure 1: The three actors cross-talking in the epidermis: the nociceptors, keratinocytes and immune-competent cells.

These actors define the peripheral wind-up mechanism. By applying peripherally acting topical analgesics, for instance based on the broad acting sodium channel blocker phenytoin as an active pharmaceutical ingredient (API), we can silence the pathological excitatory output of the small nerve fibers. All elements of this cross-talking triad possess sodium channels. Peripheral sensitization is an integral part of neuropathic pain, but it is not currently in the focus of attention as a new base for selecting treatment. This goes hand in hand with low 
interest in the value of topical analgesics for the treatment of peripheral localized neuropathic pain. Most topical formulations foe neuropathic pains are compounded, with the exception ofcapsaicin and lidocaine plasters. However, if we could target the mechanisms related to peripheral sensitization before 'chronification', for instance after mammectomy, by applying selected topical analgesic creams, we could avoid much suffering.

Therefore, it makes a lot of sense to focus a bit more on the mechanisms behind peripheral sensitization. Toexplore the links between the various pathomechanismsin different peripheral localized neuropathic pain states, and to develop putative inroads for therapy by applying different topical analgesics. It seems that phenytoin as a broad acting sodium blocker can inhibit over activity of small fibers and reduce pain in small fiber neuropathic pain and diabetic neuropathic pain [2].

Simple peripheral pathological influences may have great impact. Even anuncomplicated incision in the skin already induces a multitude of mechanisms, up to methylation of DNA, all contributing to the process of peripheral nerve sensitization, one of the fundaments of the emergence of peripheral localized neuropathic pain [3]. This is a reason to more often contemplate the use of topical analgesics after wound pain, especially to avoid winding-up phenomena and 'chronification' of pain. The fact that topical phenytoin has local analgesic properties and supports wound healing would further support the use of such compound in topical formulations [4]. In the past we described the factors leading to sensitization and its related up-regulation of targets in terms of sodium and calcium channels, local receptors and transmitters. Based on these simplistic mono-causal pathogenetic links, research models in preclinical research were selected and these models were used for many decades to screen promising molecules for their putative analgesic effects in neuropathic pain.
This simple way of reasoning, based on the neurobiology of the 20th century, seems meanwhile to be quite outdated. It did not lead to fundamental improvements of our therapeutic armamentarium of analgesic drugs from the last century. New insights however are emerging, for instance based on epigenetic mechanisms for neuropathic pain [5]. Hopefully new screening models will also be developed so that we can identify new inroads in the treatment of neuropathic pain, and not add all kinds of me-too treatments to the current pharmacotherapeutic armamentarium, based on the old ways. Dermal targeted analgesic formulations also seem to be promising in the treatment of localized peripheral neuropathic pain.

\section{Conflict of Interest}

The author is one of the patent holders of two patents related to repurposing of phenytoin: 'Topical phenytoin for use in the treatment of peripheral neuropathic pain' and 'Topical pharmaceutical composition containing phenytoin and a (co-) analgesic for the treatment of chronic pain'.

\section{References}

1. Dussor G, Koerber HR, OaklanderAL, Rice FL, Molliver DC (2009) Nucleotide signaling and cutaneous mechanisms of pain transduction. Brain Res Rev 60: 24-35.

2. Keppel Hesselink JM, Kopsky DJ (2017) Topical phenytoin cream reduces burning pain due to small fiber neuropathy in sarcoidosis. J Anesth Pain Med 2(1): 1-3.

3. Sun Y, Sahbaie P, Liang D, Li W, Shi X, et al. (2015) DNA Methylation Modulates Nociceptive Sensitization after Incision. PLoS One 10(11): e0142046.

4. Keppel Hesselink JM Phenytoin repositioned in wound healing: clinical experience spanning 60 years. Drug Discov Today. 2017 Oct 6. pii: S1359-6446(17)30096-X. doi: 10.1016/j.drudis.2017.09.020.

5. Ligon CO, Moloney RD, Greenwood-Van Meerveld B (2016) Targeting Epigenetic Mechanisms for Chronic Pain: A Valid Approach for the Development of Novel Therapeutics. J PharmacolExpTher 357(1): 8493.

\section{Your next submission with Juniper Publishers will reach you the below assets}

- Quality Editorial service

- Swift Peer Review

- Reprints availability

- E-prints Service

- Manuscript Podcast for convenient understanding

- Global attainment for your research

- Manuscript accessibility in different formats

( Pdf, E-pub, Full Text, Audio)

- Unceasing customer service

Track the below URL for one-step submission https://juniperpublishers.com/online-submission.php 